Agata Sowińska ${ }^{1}$

\title{
Fragmenta i testimonia hermetyczne u autorów różnych. Wstępny przegląd źródel ${ }^{2}$
}

Zasób „świadectw” i „fragmentów” hermetycznych w formie krytycznych edycji tekstów źródłowych oraz ich przekładów (z komentarzem) oferują obecnie dwa czterotomowe zagraniczne korpusy tekstów, zazwyczaj $^{3}$ tych z gatunku tzw. hermetyzmu wyższego, a zatem, posiłkując się wyjaśnieniem terminu z publikacji wcześniejszej dotyczącej zagadnień hermetyzmu4, utworów natury religijno-filozoficznej, jak łaciński traktat Asclepius, siedemnaście traktatów/dialogów stanowiących zbiór o nazwie Corpus Hermeticum, dwadzieścia dziewięć ${ }^{5}$ tekstów i fragmentów hermetycznych w Antologii Stobajosa, trzy teksty

1 Dr Agata Sowińska, doktor nauk humanistycznych (filolog klasyczny), adiunkt w Instytucie Literaturoznawstwa na Wydziale Humanistycznym Uniwersytetu Śląskiego w Katowicach; e-mail: agata.ewa.sowinska@gmail.com; ORCID: 0000-0002-3399-3200.

2 Niniejszy artykuł stanowi przyczynek do przygotowywanej publikacji tzw. tetralogii hermetycznej mego autorstwa, a więc czterotomowego przekładu (ze wstępem i komentarzem) na język polski tekstów hermetyzmu wyższego (w wersji synoptycznej obejmującej przekłady ekwiwalentów starogreckich, łacińskich i koptyjskich) oraz ,świadectw” i „fragmentów” hermetycznych u autorów różnych. Tom czwarty tetralogii ma obejmować fragmenta i testimonia hermetyczne.

3 Pewne wyjątki mogą być dostrzegalne właśnie w tomach zawierających wykazy „świadectw” i „fragmentów”, zwłaszcza biorąc pod uwagę atrybucję niektórych testimoniów oraz tekstów zawierających hermetyczne excerpta. Zob. np. Zosimus: Perì orgánōn kaì kamínōn.

4 A. Sowińska, Hermetica średniowiecza i renesansu. Studium z historii myśli europejskiej, Katowice 2018, s. 10, przyp. 2.

5 Celowa korekta liczby fragmentów u Stobajosa w porównaniu z pierwotną podaną w monografii, zob. przyp. 4. 
w szóstym kodeksie Biblioteki z Nag Hammadi, Definicje z Armenii (Armenian Hermetic Definitions) oraz tzw. fragmenty wiedeńskie (Vienna fragments). Hermetyzm ,niższy” stanowią natomiast teksty o treści magicznej, alchemicznej, astrologicznej, w których głównym wyznacznikiem ich przynależności do pism hermetycznych jest występowanie postaci Hermesa Trismegistosa (również jako np. Hermes Mercurius Trismegistus). Polskie nazewnictwo dotyczące podziału hermetyzmu na hermetyzm wyższy i hermetyzm niższy występuje (najprawdopodobniej po raz pierwszy) w tekstach Tadeusza Zielińskiego ${ }^{6}$. Podział literatury hermetycznej przedstawiony został również (mniej więcej w tym samym czasie co podział hermetyzmu Zielińskiego) przez filologa klasycznego Waltera Scotta, który wprowadza pojęcia religious, philosophic Hermetica (w stosunku do hermetyzmu wyższego) oraz occult arts, sciences (dla hermetyzmu niższego) $)^{7}$. Bardzo ważną postacią, która m.in. miała wpływ na nazewnictwo podziału literatury hermetycznej, jest filozof i filolog, francuski dominikanin André-Jean Festugière i jego hermétisme savant (w odniesieniu do hermetyzmu wyższego) oraz hermétisme populaire (sc. hermetyzm popularny, niższy $)^{8}$.

Pionierskie i dające szerokie możliwości badawcze (aczkolwiek ze względu na wyjątkowo liczne emendacje i transpozycje uchodzące za hiperkrytyczne) dwudziestowieczne wydanie Hermetica autorstwa W. Scotta ${ }^{9}$ oraz dziś wiodące autorstwa angielskiego filologa klasycznego i teologa Arthura Darby'ego Nocka wraz ze wspomnianym wcześniej A.-J. Festugière' $\mathrm{em}^{10}$ stanowią obecnie punkt odniesienia do dalszych

6 Zob. T. Zieliński, Hermes Trzykroć-Wielki (Hermes Trismegistos). Studium z cyklu: wspótzawodnicy chrześcijaństwa, Zamość 1921.

7 Zob. W. Scott, Hermetica. The ancient Greek and Latin writings which contain religious or philosophic teachings ascribed to Hermes Trismegistus, t. 1, Boston 1985.

8 Zob. A.-J. Festugière, La Révélation d'Hermes Trismégiste, t. 1, Paris 1950.

9 W. Scott, Hermetica. The ancient Greek and Latin writings which contain religious or philosophic teachings ascribed to Hermes Trismegistus, t. 1-4, Boston 1985 (wyd. 1, 1924).

10 A.D. Nock - A.-J. Festugière, Hermès Trismégiste. Corpus Hermeticum, t. 1-4, Paris 2007-2011 (wyd. 1, 1946-1954). 
badań nad literaturą hermetyczną. Ci ostatni pod względem doboru „fragmentów" hermetycznych powołują się w swym, jednak skromniejszym, jeśli chodzi o excerpta, francuskim wydaniu ${ }^{11}$ na bardziej rozbudowany tom ,świadectw” Scotta ${ }^{12}$.

\section{Antologia Scotta}

Scott pod jednym tytułem Testimonia tworzy w latach dwudziestych XX wieku korpus ,świadectw” oraz „fragmentów” hermetycznych występujących $\mathrm{w}$ tekstach autorów różnych z czasów po narodzeniu Chrystusa, uwzględniając w swym zbiorze twórców m.in. chrześcijańskich, jak i żydowskich czy też arabskich. Nie dokonuje jednakowoż w swym katalogu wyimków wewnętrznego podziału na „świadectwa” i „fragmenty”. W przypadku zaakcentowania prawdopodobnego cytatu $\mathrm{z}$ danego pisma hermetycznego Scott przyjmuje w swej antologii zasadę kopiowania $\mathrm{z}$ tekstów autorów różnych tylko tych fraz, które mogą pochodzić z utworów hermetycznych (pomijając jednakże niektóre elementy - nie skopiował np. istotnej starogreckiej wersji traktatu Asclepius poświadczonej u Laktancjusza), i umieszczania tychże wyimków w osobnym skromnym dziale Fragmenta ${ }^{13}$, zachowując je zarazem

11 A.D. Nock - A.-J. Festugière, Hermès Trismégiste. Corpus Hermeticum, t. 4, Paris 2009.

12 W. Scott, Hermetica. The ancient Greek and Latin writings which contain religious or philosophic teachings ascribed to Hermes Trismegistus, t. 4, Boston 1985.

13 Zob. W. Scott, Hermetica. The ancient Greek and Latin writings which contain religious or philosophic teachings ascribed to Hermes Trismegistus, t. 1, Boston 1985, s. 534-549. Autorzy, których fragmenty dzieł W. Scott skopiował do działu Fragmenta, to Tertulian (De anima 33), Cyprian (?) (Quod idola dii non sint 6), Laktancjusz (Divinae institutiones $1,6,4 ; 1,7,2 ; 1,11,6 ; 2,8,48 ; 2,8,68 ; 2,10,14 ; 2,14,6 ; 2,15,6 ; 4$, 7, 3; 4, 8, 5; 4, 13, 2; 7, 9, 11; 7, 13, 3; Epitome 4, 4; 4, 9, 3; 14, 3; 37, 8), Jamblich (cyt. w: Proclus: In Timaeum 117D; Abbamonis ad Porphyrium responsum 8, 6a; 10, 7), Zosimos (Perì orgánōn kai kamínōn = Gnếsia hypomnémata perì tồ $\Omega$ stoichềou i.4; i.5; i.7), Efrem Syryjczyk (Prose refutation against Mani), Dydym z Aleksandrii (De Trinitate 757B; 756B), Cyryl z Aleksandrii (Contra Iulianum 549 C i D; 552 D; 553 A i B; 556A 
w określonym kontekście w dziale Testimonia. Przykładowy wyraźny podział na testimonia i fragmenta przyjmuje natomiast M. David Litwa z Australijskiego Uniwersytetu Katolickiego, który w swej, stosunkowo nowej (z 2018 roku) pozycji wydawniczej obejmującej wypisy hermetyczne, wydanej przez Cambridge University Press jedynie w formie anglojęzycznej translacji źródeł (a więc bez edycji tekstów, w przeciwieństwie do omawianych tu wydawnictw), gromadzi i względnie weryfikuje (w tym precyzuje i/lub zawęża) dotychczas znane „świadectwa” i „wyciągi”, jak i - co istotne - testimonia i fragmenta hermetyczne jeszcze nieodnotowane przez innych kompilatorów ${ }^{14}$.

W monumentalnym korpusie Scotta zostały zebrane i wydane (w oryginale lub przekładzie) oraz opracowane wyimki źródłowe, treściowo odnoszące się według niego do zagadnienia hermetyzmu, hermetycznych tekstów tudzież do postaci samego Hermesa Trismegistosa. Katalog ekscerptów otwiera u Scotta Athenagoras, Libellus ${ }^{15}$ pro Christianis $28^{16}$ (textus Graecus ${ }^{17}$ ), po którym następują kolejno

i B; 588A, B i C; 920 D), Pseudo-Antimus (Anthímou episkópou Nikomēdias kaì mártyros ek tôn pròs Theódōron perì tês hagías ekklēsías 15) i Shahrastani (Book of Religions and Sects). Zob. dalej: Antologia Scotta.

14 Zob. M.D. Litwa, Hermetica II. The Excerpts of Stobaeus, Papyrus Fragments, and Ancient Testimonies in an English Translation with Notes and Introduction, Cambridge 2018. Ze względu na inny charakter publikacyjny (przekład ze wstępem i skromnym komentarzem) w niniejszym artykule jedynie nawiązuję do korpusu Litwy (odwołania do Litwy podaję w przypisach) w przypadku występowania wyraźnych oboczności w porównaniu z edycją W. Scotta stanowiącą zasadniczy punk odniesienia do dalszych badań nad „świadectwami” i „fragmentami” hermetycznymi u autorów różnych, czego dowodem jest chociażby wspomniana wyżej publikacja Arthura Darby’ego Nocka i Anrdé-Jeana Festugière'a oraz najnowsza M.D. Litwy.

15 Litwa: Legatio pro Christianis.

16 Dokładną lokalizację ,świadectwa/fragmentu” hermetycznego w danym tekście podaję za edycją W. Scotta.

17 Textus Graecus (termin techniczny; dalej także textus Latinus, textus Latinus cum fragmentis Graecis, translatio Anglica, translatio Latina) - język przytaczanego przez W. Scotta tekstu źródłowego przyjęty w wydaniu jego autorstwa. Por. terminy przyjęte np. przez wydawców tekstów hermetyzmu niższego w: Hermetis Trismegisti astrologica et divinatoria, Corpus Christianorum. Continuatio Mediaevalis 144C, Turnhout 2001. 
Tertullianus, Adversus Valentinianos 15 (textus Latinus), De anima 2, 28, 33 (textus Latinus) ${ }^{18}$; Pseudo-Cyprianus, Quod idola dii non sint 6 (textus Latinus) $^{19}$; Pseudo-Iustinus, Cohortatio ad gentiles 36E-37B (textus Graecus) ${ }^{20}$; Arnobius, Adversus nationes 2, 13 (textus Latinus); Lactantius: Divinae institutiones $1,6,1-5 ; 1,7,2 ; 1,11,61 ; 2,8,48 ; 2$, 8,$68 ; 2,10,3-15 ; 2,12,4-14 ; 2,14,1-2,15,8 ; 4,6,1-4,13,5 ; 4,27$, 18-20; 5, 14, 9-12; 6, 25, 1-12; 7, 4, 3; 7, 9, 11; 7, 13, 1-4; 7, 14, 9-7, 18, 5 (textus Latinus cum fragemntis Graecis; por. Epitome 4, 4 sq., 14, 2-4; 37, 1-9 - textus Latinus) ${ }^{21}$, De ira Dei, 2, 2 sq. (textus Latinus) $)^{22}$; Abammon, Abammonis ad Porphyrium responsum = Iamblichus, De mysteriis (?) (textus Graecus) ${ }^{23}$; Iamblichus $\rightarrow$ Proclus: In Timaeum 116F-117D (textus Graecus)24; Zosimus Panopolitanus (Panopolites), Perì orgánōn kaì kamínōn = Gnésia hypomnếmata perì toû $\Omega$ stoicheîou (textus Graecus) ${ }^{25}$; Marcellus Ancyranus $\rightarrow$ Eusebius, Contra Marcellum 1, 4 § 39 sqq. (textus Graecus)26; [Pseudo-Anthimus,] Anthímou episkópou Nikomēdías kaì mártyros ek tôn pròs Theódōron

18 Litwa nadaje wyimkom z utworów Tertuliana status „fragmentów” (FH Fragmenta Hermetica).

19 U Litwy jako $F H$.

20 Litwa nie odnotowuje tego źródła.

21 U Litwy jako $F H$.

22 Litwa nie odnotowuje tego źródła.

23 Według Scotta atrybucja niejasna: „Księga powszechnie, lecz błędnie tytułowana Iamblichi de mysteriis (Aegyptiorum) liber została napisana w odpowiedzi na list Porfiriusza skierowany do egipskiego kapłana - Anebo. [...] Odpowiedź miała zostać napisana przez egipskiego kapłana o imieniu Abammon [a więc zgodnie z tytułem widniejącym na MSS]. Jednak na niektórych MSS tytuł poprzedzony jest notką informującą, że Proklos, w swym komentarzu do Plotyna, nadmienił, iż autorem tejże księgi jest Jamblich. Ta anonimowa notka jest jedynym dowodem na autorstwo Jamblicha". Zob. Scott, Hermetica, t. 4, s. 40-41. Litwa: De mysteriis 1, 1-2 i 8, 4 zalicza do testimoniów hermetycznych ( $\mathrm{TH}$ - Testimonia Hermetica), a De mysteriis 8,$6 ; 10,7-$ do $F H$.

\footnotetext{
24 U Litwy jako $F H$.

25 U Litwy jako $F H$.

26 Litwa nie odnotowuje tego źródła.
} 
perì tês hagías ekklēsías (textus Graecus) ${ }^{27}$; Ephraem Syrus, Discourse against Mani ${ }^{28} /$ Prose refutation against Mani $^{29}$ (translatio Anglica) ${ }^{30}$; Filastrius Brixiensis, Diversarum hereseon liber 10: Heliognosti 103/75; Haeresis Hermis (sic!) Trismegisti de Pecoribus et Sideribus (textus Latinus); Didymus Alexandrinus, De Trinitate 2, 3 (465 A, B; 476 A, B, C; 477 A, B); 2, 27 (753 A, B; 756 A, B; 757 A, B; 760 A, B, C; 761 A); 3, 1 (773 B, C; 776 A; 780 C, D) (textus Graecus) ${ }^{31}$; Ammianus Marcellinus, Res gestae 21, 14 (textus Latinus); Augustinus, De civitate Dei 8, 22-27; 18, 39 (textus Latinus) ${ }^{32}$; Cyrillus Alexandrinus, Contra Iulianum 1 (541 init., A, C; 544 C; 545 A, B, D; 548 A, B, C, D; 549 A, B, C, D; 552 A, C, D; 553 A, B, C, D; 556 A, B, C, D); 2 (580 A(?), B, C, D; 581 A; 585 D; 588 A, B, D; 597 D; 600 A, B); $4(700$ D; 701 A, B); 5 (769 A, B); 8 (920 C, D, B (sic!)) + addendum, Analecta Sacra et Classica, t. 5, p. 291 - Cod. Vat. 1198; p. 305 - Cod. Vat. 2200, p. 444 (textus Graecus) ${ }^{33}$; excerpta e Theosophia $\$ 44$ (textus Graecus); Fulgentius, Mitologiarum libri tres 1, 15 (Fabula de novem Musis) (textus Latinus) ${ }^{34}$; Ioannes Lydus, De mensibus 4, 7; 4, 32; 4, 53; 4, 64;

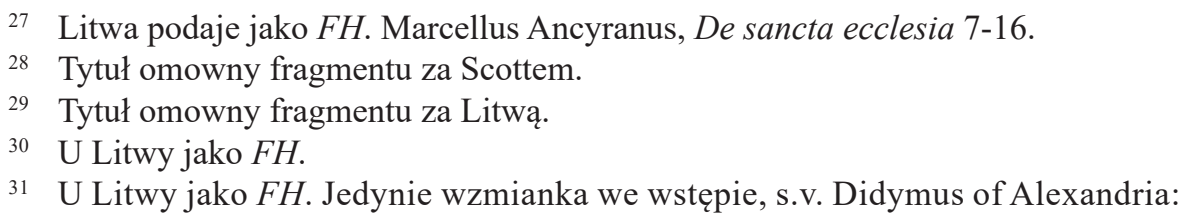
„Jeśli Didymus jest autorem De Trinitate, cytował ze zbioru przynajmniej trzech traktatów Hermesa (adresowanych) do Asklepiusza. Cyryl Aleksandryjski później umieścił te cytaty w Contra Iulianum. Didymos znał także treści nazywane dziś $\mathrm{CH} 6$ [sc. Corpus Hermeticum, utwór nr 6] i prawdopodobnie CH 13". Zob. Hermetica, tł. Litwa, s. 232.

32 Litwa De civitate Dei 8, 23-26 zalicza do FH. Ponadto De civitate Dei 18, 8 i 18, 39 zalicza do TH. Podaje przy Augustynie także nowe testimonium: Contra Faustum 13, $1 ; 13,15$.

33 Litwa Contra Iulianum 1, 43, 14-29; 1, 44, 1-11; 1, 46, 9-12; 1, 46, 13-18; 1, 46, 19-28; 1, 46, 29-34; 1, 48, 14-1, 49, 1; 1, 48, 8-17; 2, 29, 19-2, 30, 8; 2, 30, 9-11; 2, 30, 12-18; 2, 31, 10-16; 8, 31-24 zalicza do FH, Contra Iulianum 1, 41 - do TH. Litwa posługuje się wydaniem współczesnym (z lat 2016-2017, ed. Ch. Riedweg et al.), stąd możliwa różnica $\mathrm{w}$ numeracji.

34 Litwa nie odnotowuje tego źródła. 
4, 149 (textus Graecus) 35 ; Ioannes Malalas, Chronicon według PG 97, 92 (textus Graecus); por. Chronicon Paschale według PG 92, 169-171 (textus Graecus) $^{36}$; Liber Suda: s.v. Hermês ho Trismégistos; Cedrenus, Historiae compendium według PG 121, 64 (textus Graecus) 37; Īónnēs

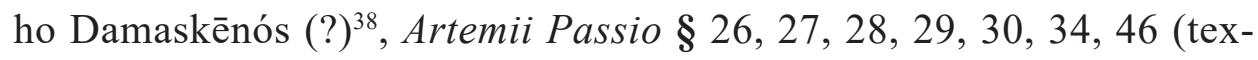
tus Graecus); Michael Psellos, Allēgoría perì toû Tantálou (textus Graecus); Apología hypèr tô̂ Nomophýlakos katà toû Ophrydâ (textus Graecus); Perì energeías daimónōn diálogos (textus Graecus); scholium in Corpus Hermeticum 1, 18 (według Scotta atrybucja schol. niepewna; textus Graecus); Nicephorus Gregoras, Explicatio in librum Synesii de insomniis według PG 149, 539B-541B (textus Graecus) ${ }^{39}$; Al-Kindí $\rightarrow$ An-Nadím ${ }^{40}$, Fihrist-el-'Ulûm ${ }^{41}$ 9, 1 § 1, 2-8, 11-12 (translatio Anglica); Al-Maqdisí, The Book of Creation and History według C. Huarta ${ }^{42}$

35 Litwa zalicza wymienione fragmenty do $F H$.

36 U Litwy: Chronographia 2, 4; 13, 36 jako $F H$.

37 Litwa nie odnotowuje tego źródła bezpośrednio, a zaznacza jedynie, że Cedrenus zaadaptował dany fragment za pośrednictwem tekstu Malalasa (Chronografia). Zob. Hermetica, tł. Litwa, s. 216, przyp. 8.

38 Tak ma Litwa (zob. Hermetica, tł. Litwa, s. 295, przyp. 1). Scott nie wskazuje autora, ale podaje przyjmowane wersje atrybucyjne: (1) autorem jest bliżej nieznany Iōánnēs monachòs ho Rhódios, (2) Iōánnēs monachòs ho Rhódios to Jan z Damaszku (zob. Scott, Hermetica, t. 4, s. 236, przyp. 1).

39 Litwa nie odnotowuje tego źródła.

40 Oprócz autorów Al-Kindí i An-Nadím Litwa nie przytacza żadnej innej postaci podanej w tym momencie przez Scotta. Dodaje natomiast innych arabskich autorów: Abū Ma'shara i Al-Mubaššir ibn Fātika. Od tego momentu Litwa nie odnotowuje w swym korpusie „fragmentów” i ,świadectw” rożnych autorów już praktycznie żadnych źródeł zasugerowanych przez Scotta.

41 Przyjęty w artykule zapis autorów oraz tytułów arabskich podaję za Scottem. Więcej na temat hermetyzmu arabskiego zwłaszcza w: K. van Bladel, The Arabic Hermes: From Pagan Sage to Prophet of Science, New York 2009; Dictionary of Gnosis and Western Esotericism, ed. W.J. Hanegraaff, Leiden - Bostom 2006, s.v. Hermetic Literature III: Arab.

42 Al-Maqdisí, Le livre de la création et de l'histoire, t. 1-6, ed. i tł. C. Huart, Paris 1899-1919. Scott podaje w komentarzu odnośnik do wydania tekstu źródłowego w trzech tomach (z lat 1899-1903): „,Ta księga [sc. The Book of Creation and History] (niewspomniana przez Chwolsohna) została wydana i przetłumaczona przez Klemensa Huarta, 3 vols., 1899-1903". Zob. Scott, Hermetica, t. 4, s. 250, przyp. 4. 
t. 1, p. 130 (translatio Anglica); Al-Mas'údí, Kitábu'l-Tambíh wa-'lIshráf $\rightarrow$ Al-Maqrízí, Al-Chitat (?) ${ }^{43}$ według D. Chwolsohna ${ }^{44}$, t. 2, p. 604 (translatio Anglica), Murúju l'Dhahab według D. Chwolsohna t. 2, p. 372, 621, 622, 642 (translatio Anglica); An-Nadím, Fihrist-el'Ulûm 10 według D. Chwolsohna, t. 1, p. 788 (translatio Anglica); Ibn Zuláq $\rightarrow$ Yáqút, Geographical Dictionary według D. Chwolsohna, t. 2, p. 629 (translatio Anglica); Ibn Hazm Al-Qorthobí, Book of Religions and Sects według D. Chwolsohna, t. 2, p. 526: „Concerning the Jews, and those Christians who deny the Trinity, and those of the Magians and Sabians who acknowledge the unity of God [...]" (translatio Anglica); Ibráhím Bin Wassíf Sháh według D. Chwolsohna, t. 2, p. 534 (translatio Anglica); Al-Shahrastání, Book of Religions and Sects według D. Chwolsohna, t. 2, p. 415-450, § 6-27, 30, 32-34 (translatio Anglica); 'Umar Bin Chidhr Isfahání, „Concerning the principles of the religion of the Sabians" według D. Chwolsohna, t. 2, p. 517 (translatio Anglica); Suhrawardí, The Philosophy of Illumination według M. Horten ${ }^{45}$, p. 2-3, 44, 45 sq., 47, 61-62, 69 (translatio Anglica); Maimonides, Guide to the perplexed według D. Chwolsohna, t. 2, p. 461 (translatio Anglica); Al-Qiftí, Lives of wise men według D. Chwolsohna, t. 1, p. 790 (zob. także D. Chwolsohna, t. 2, p. 529), t. 2, p. 532 (translatio Anglica); AlKátibí według D. Chwolsohna, t. 2, p. 492 sqq. (translatio Anglica); Bar Hebraeus, Historia dynastiarum według E. Pococke ${ }^{46}$, p. 6 sqq., 184 (translatio Latina); Hermes (sic!), De castigatione animae według Bardenhewera $^{47}$, cap. $1, \S 1-11$; cap. 2, § 1-15; cap. 3, § 1-13; cap. 4,

43 Scott nie podaje wprawdzie tytułu źródła, z którego zaczerpnął testimonium, ale przytacza autora, co pozwala zaproponować tytuł. Zob. krótki wstęp do tego testimonium: „Al-Maqrizi (który zmarł w 1442 r. po Chrystusie) cytuje Masudiego, Kitábu'l-Tambíh wa- 'l-Ishráf, w następujący sposób [...]'.'Scott, Hermetica, t. 4, s. 253, s.v. Mas ‘údí.

44 D. Chwolsohn, Die Ssabier und der Ssabismus, t. 1-2, St. Petersburg 1856.

45 M. Horten, Die Philosophie der Erleuchtung nach Suhrawardi, Halle 1912.

46 Bar Hebraeus, Historia dynastiarum, ed. i tł. E. Pococke, Oxford 1663.

47 Hermetis Trismegisti de castigatione animae libellus, ed. i tł. O. Bardenhewer, Bonn 1873. 
§ 1-14; cap. 5, § 1-13; cap. 6, § 1-15; cap. 7, § 1-11; cap. 8, § 1-14; cap. 9, § 1-11; cap. 10, § 1-9; cap. 11, §1-12; cap. 12, § 1-10; cap. 13, § 1-9; cap. 14, § 1-15b (translatio Anglica).

Na powyższe źródłowe excerpta powołują się także w swym francuskim wydaniu A.D. Nock i A.-J. Festugière ( $\rightarrow$ t. 4$)$, zawężając zbiór do łącznie trzydziestu sześciu cytowań źródłowych w edycji z przekładem francuskim z: Tertullianus, De anima; Pseudo-Cyprianus, Quod idola dii non sint; Lactantius, Divinae institutiones i Epitome; Iamblichus, De mysteriis i Iamblichus w: Proclus, In Timaeum; Zosimus, Gnếsia hypomnémata perì tôิ $\Omega$ stoicheîou; Ephraem Syrus, Discourse against Mani / Prose refutation against Mani ${ }^{48}$ - ten ostatni u Nocka i Festugière'a tylko w przekładzie francuskim; Bar Hebraeus, Le Candélabre des Sanctuaires, Troisième base: de la Théologie, cap. 9: Trinité des Personnes - także u Nocka i Festugière'a tylko w przekładzie francuskim oraz Cyrillus Alexandrinus, Contra Iulianum; Ps.-Anthimus, jak i Ioannes Lydus, De mensibus.

\section{Addendum}

Oprócz źródeł wzmiankowanych powyżej Litwa sugeruje włączyć do katalogu autorów różnych, powołujących się na założenia hermetyczne lub chociażby wzmiankujących o Hermesie, dodatkowe postacie, takie jak: Artapanus (fragment cytowany przez Euzebiusza ${ }^{49}$ ), Cyceron $^{50}$, Maniliusz $^{51}$, Trazyllos ${ }^{52}$, Doroteusz z Sydonu ${ }^{53}$, Filon z Byblos (podobnie jak Artapanus cytowany przez Euzebiusza ${ }^{54}$ ), Pseudo-Maneton (cytowa-

\footnotetext{
48 Podaję omownie za Scottem i Litwą.

49 Eusebius, Praeparatio Evangelica 9, 27, 4-9.

50 Cicero, De natura deorum 3, 56.

51 Manilius, Astronomica 1, 25-37.

52 Thrasyllus, Pinax.

53 Dorotheus Sidonius, Carmen Astrologicum 2, 20, 1. Zob. także: scholium in Hephaestionis Apotelesmatica 3, 6, 11.

54 Eusebius, Praeparatio Evangelica 1, 9, 24.
} 
ny przez Syncellusa ${ }^{55}$ ), Mariusz Wiktoryn ${ }^{56}$, Cesarz Julian (cytowany przez Cyryla z Aleksandrii ${ }^{57}$ ), Hermiasz ${ }^{58}$, Izydor z Sewilli ${ }^{59}$, Grzegorz z Nazjanzu ${ }^{60}$, Gajusz Juliusz Romanus (cytowany przez Charyzjusza ${ }^{61}$ ), Quodvultdeus ${ }^{62}$, Albert Wielki ${ }^{63}$, Mikołaj z Kuzy ${ }^{64}$ - wymienieni tu także zawarli w swej twórczości informacje dotyczące samej postaci Hermesa Trismegistosa, jak w przypadku pierwszych jedenastu oraz Alberta Wielkiego i Mikołaja z Kuzy, lub wykorzystali w swym dyskursie fragmenty hermetyczne, jak pięciu ostatnich.

Powyższy przyczynek pokazuje zakres wpływu tekstów hermetycznych i postaci Hermesa Trismegistosa na literaturę, począwszy od starożytności po średniowiecze. Późne średniowiecze oraz czasy nowożytne obfitują już w fascynacje swego rodzaju recepcją hermetyczną dzięki translacji starogreckich tekstów hermetycznych przez uczonych pokroju Marsilia Ficina, który jako pierwszy zmierzył się w 1463 roku z przywiezionymi z Macedonii przez mnicha czternastoma tekstami hermetycznymi (stopniowo odkrywano kolejne), przekładając je na łacinę i dając tym samym grunt pod narodziny tradycji hermetycznej, która nieprzerwanie trwa do dziś, stając się w XXI wieku specjalizacją akademicką, czego dowodem jest chociażby międzynarodowe Center for History of Hermetic Philosophy and Related Currents (HHP) przy Uniwersytecie Amsterdamskim.

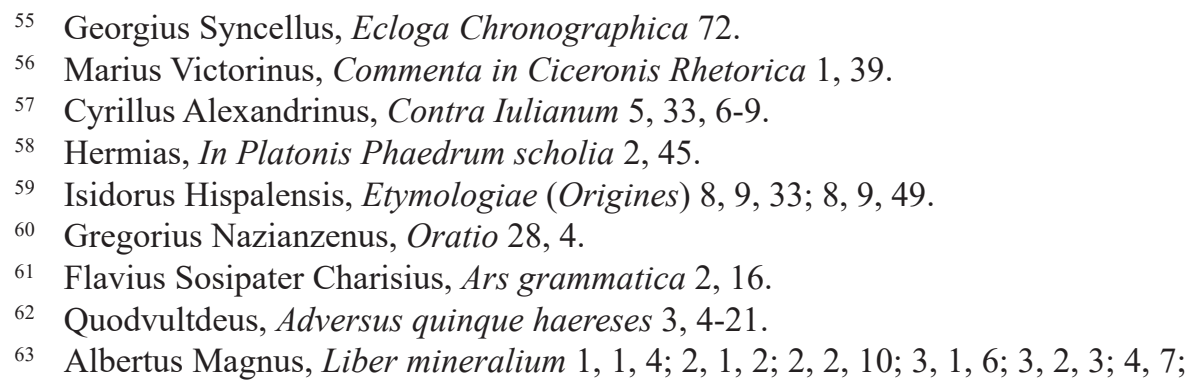
Albertus Magnus, De intellectu et intelligibili 2, 1, 6; 2, 1, 9; Albertus Magnus, De somno et vigilia 3, 1, 5; Albertus Magnus, Liber Ethicorum 10, 2, 3; Albertus Magnus, De animalibus 22, 1, 5; 25, 2; Albertus Magnus, Liber de causis et processu universitatis 1, 4, 3.

64 Nicolaus Cusanus, De docta ignorantia 1, 24; 1, 25; 2, 8; Nicolaus Cusanus, De dato patris luminum 2, nr 102; Nicolaus Cusanus, De beryllo 7. 


\section{Hermetic Fragments and Testimonies from Various Authors. The Preliminary Research on the Literary Sources}

(summary)

This contribution provides an insight into the history of hermetic literature in the area of its influence on the literary sources of the ancient times and the Middle Ages. The article is a reference point for further research on the use of hermetic literature in literary discourse - especially within religious and philosophical themes.

Keywords: fragments; testimonies; Hermetism; W. Scott; A.D. Nock; A.-J. Festugière; M.D. Litwa

\section{Fragmenta i testimonia hermetyczne u autorów różnych. Wstępny przegląd źródeł}

(streszczenie)

Niniejszy przyczynek daje możliwość wglądu w historię literatury hermetycznej w obszarze jej oddziaływania na słowo pisane czasów zamierzchłych po średniowiecze. Artykuł stanowi punkt odniesienia do dalszych badań nad wykorzystaniem literatury hermetycznej w dyskursie literackim, zwłaszcza w obrębie tematyki religijno-filozoficznej.

Słowa kluczowe: fragmenta; testimonia; hermetyzm; W. Scott; A.D. Nock; A.-J. Festugière; M.D. Litwa

\section{Bibliografia}

Al-Maqdisí, Le livre de la création et de l’histoire, t. 1-6, ed. i tł. C. Huart, Paris 1899-1919.

Bar Hebraeus, Historia dynastiarum, ed. i tł. E. Pococke, Oxford 1663.

Bladel K. van, The Arabic Hermes: From Pagan Sage to Prophet of Science, New York 2009.

Chwolsohn D., Die Ssabier und der Ssabismus, t. 1-2, St. Petersburg 1856.

Dictionary of Gnosis and Western Esotericism, red. W.J. Hanegraaff, Leiden - Boston 2006.

Festugière A.-J., La Révélation d'Hermes Trismégiste, t. 1, Paris 1950. 
Hermetica II. The Excerpts of Stobaeus, Papyrus Fragments, and Ancient Testimonies in an English Translation with Notes and Introduction, t1. M.D. Litwa, Cambridge 2018.

Hermès Trismégiste. Corpus Hermeticum, t. 1-4, ed. i tł. A.D. Nock - A.-J. Festugière, Paris 2007-2011.

Hermetis Trismegisti astrologica et divinatoria, Corpus Christianorum. Continuatio Mediaevalis 144C, Turnhout 2001.

Hermetis Trismegisti de castigatione animae libellus, ed. i tł. O. Bardenhewer, Bonn 1873.

Horten M., Die Philosophie der Erleuchtung nach Suhrawardi, Halle 1912.

Scott W., Hermetica. The ancient Greek and Latin writings which contain religious or philosophic teachings ascribed to Hermes Trismegistus, t. 1-4, Boston 1985.

Sowińska A., Hermetica średniowiecza i renesansu. Studium z historii myśli europejskiej, Katowice 2018.

Zieliński T., Hermes Trzykroć-Wielki (Hermes Trismegistos). Studium z cyklu: wspótzawodnicy chrześcijaństwa, Zamość 1921. 